\title{
NUMERICAL INVESTIGATION OF THE SPRAY CHARACTERISTICS IN AN OUTWARDLY-OPENING PIEZOELECTRIC GASOLINE INJECTOR FOR DIFFERENT AMBIENT CONDITIONS
}

\author{
İbrahim TAS \\ Mehmet İhsan KARAMANGí
}

Received: 26.02.2019 ; revised: 02.05.2019; accepted: 10.05.2019

\begin{abstract}
In this study, the spray characteristics of an outwardly-opening injector have been investigated numerically. Numerical analyses are carried out by taking temperature and pressure statuses of the internal combustion engine in cold temperature operations into consideration. The effects of these parameters on the evaporation rate, penetration, spray morphology, angle of the fuel spray and the Sauter Mean Diameter were key issues to be addressed. N-heptane fuel was used and the Kelvin-Helmholtz / Rayleigh-Taylor breakup model was adopted. The analyses were performed in the comprehensive environment of Fluent software. It was observed that the results complied with experimental data taking part in literature. Consequences demonstrated that increasing the ambient pressure intensified vortex formation, decreased penetration and increased fuel cone angle by forming a more compact fuel bundle. In addition, it was ascertained that the effect of the temperature parameter on the evaporation was less effective than the pressure parameter.
\end{abstract}

Keywords: spray atomization and characteristics, mixture formation, hollow cone spray, KH-RT

\section{Farkı Ortam Koşullarında Dışa Doğru Açılan Piezoelektrik Benzin Enjektöründe Püskürtme Karakteristiklerinin Sayısal Olarak İncelenmesi}

Öz: $\mathrm{Bu}$ çalışmada, dışa doğru açılan bir enjektörün püskürtme karakteristikleri nümerik olarak incelenmiştir. Soğukta ilk çalıştırmada içten yanmalı motorun sıcaklık ve basınç durumları dikkate alınarak nümerik analizler yapılmıştır. $\mathrm{Bu}$ parametrelerin buharlaşma hızı, penetrasyon, püskürtme morfolojisi, yakıt püskürtme açısı ve Sauter Ortalama Çapı üzerindeki etkileri ele alınmıştır. N-heptan yakıtı kullanılmış ve Kelvin-Helmholtz / Rayleigh-Taylor ayrılma modeli benimsenmiştir. Analizler, Fluent yazılımı ile kapsamlı olarak gerçekleştirilmiştir. Sonuçların literatürde yer alan deneysel verilerle uyum içinde olduğu görülmüştür. Artan ortam basıncı vorteks oluşumunu şiddetlendirmiş, yakıt nüfuziyet derinliğini azaltmış ve daha kompakt bir yakıt demeti oluşturarak yakıt püskürtme açısını azaltmıştır. Ayrıca, sıcaklık parametresinin buharlaşma üzerindeki etkisinin basınç parametresinden daha az etkili olduğu tespit edilmiştir.

Anahtar Kelimeler: püskürtme atomizasyonu ve karakteristiği, karışım oluşumu, içi boş koni püskürtme, KH-RT

\footnotetext{
* Departmant of Automotive Engineering, Faculty of Technology, Pamukkale University, 20160, Turkey *** Departmant of Automotive Engineering, Faculty of Engineering, Bursa Uludag University, 16059, Turkey Correspondence Author: İbrahim TAŞ (itas@pau.edu.tr)
} 
Taş I.,Karamangil M.I...: Num. Inv. Of The Spr. Char. In OutWrd-Opn. Piezoel. Gas Inj. For Dif. Amb. Cond.

\section{INTRODUCTION}

The transformation of the internal combustion engines from larger to smaller volumes has been necessitated due to increasing concern of fossil fuel issues stemming from the oil crisis in 1970. The fact that the oil-based fuels used by the internal combustion engines are not unlimited has led authorities to conduct serious researches in order to increase the efficiency in defiance of decreasing engine volumes. What is more, by 1990 , lower fuel consumption and lower rate of emission release have become a legal requirement. As an ideal alternative to the solution of this problem, gasoline direct injection (GDI) engines have emerged. The performance of these engines increases while reducing fuel consumption. Particularly, spray-guided GDI engines reduce emissions and fuel consumption while increasing engine performance. In gasoline direct injection engines, the formation of the mixture plays a major role in fuel consumption, emissions and engine performance (V. Basshuysen, 2009; Stiesch, 2003; Baumgarten, 2006).

The air-fuel mixture is poor due to the lack of evaporation in port spray gasoline engines; hence, the mixture is required to be enriched a little. The GDI engine operating in stratified charging mode produces a cleaner exhaust gas than it is the case with port injection gasoline engines (Dahlander et al., 2008). The production of clean exhaust gas in the direct fuel injection spark-ignition engines depends directly on the quality of combustion. The quality of the combustion depends on many characteristics of the engine such as combustion chamber and piston shape, spark plug and injector position, particularly adequate composition of the fuel-air mixture with each other (V. Basshuysen, 2009; Stiesch, 2003; Baumgarten, 2006).

In order to benefit from the superior characteristics of GDI engines, some problems should be avoided. The most important of these problems is that a flammable mixture is formed around the spark plug at the time of combustion. It is difficult to form a flammable mixture around the spark plug in the cylinder. The shape of the fuel spray sent into the cylinder and towards to spark plug is particularly important in cold conditions. However, due to some outstanding features of the outwardly-opening type injector which is the subject of this study, it can overcome this challenge.

This injector has many outstanding features. These superior properties can be listed as shorter penetration depth, smaller Sauter Mean Diameter, reproducibility of spray, multiple injections capability and faster response time. Due to these features, the most modern directinjection gasoline engines use outwardly-opening type injectors.

In modern GDI engines, numerical modeling and imaging techniques are extensively used to figure out fuel atomization and mixture formation. Thanks to the enhancement of computer performances and the development of multidimensional computational fluid dynamics (CFD) techniques, the CFD method has become a more efficient and efficient tool to investigate the formation of the mixture and the spraying process. Several different CFD models have been developed to explain the process of fuel atomization and breakup.

In real-world applications, comprehensive model calibration works are carried out to provide proper estimates of decomposition and disintegration for different nozzles under various operating conditions.

Over the last thirty years, many researchers have done countless studies to fully understand the mechanism of breakup of the liquid fuel spray in the combustion chamber.

With an outwardly-opening piezoelectric injector, they have experimentally studied the spray characterization for the cold start conditions of the engine. The spray pressure, ambient pressure and temperature in the constant volume combustion chamber (CVCC) and then examined the variation in spray velocity and penetration. Also, they performed multiple injections in a single cycle and observed changes in spray morphology (Dahlander et al., 2008).

Wang (2019) performed the injection of an externally opened piezoelectric driven injector used in direct gasoline injection engines, numerically and experimentally, with the help of the commercially accessible computational fluid dynamics software STAR-CD. In their study, 
while the fuel temperature was $293 \mathrm{~K}$, they evaluated the robustness of the disintegration models at two different ambient pressures, 1 and 10 bar.

Das and Lim (2017) conducted physical experiments in a constant-volume combustion chamber to determine the effect of ambient pressure and temperature on spray characterization using n-heptane fuel under actual operating conditions of a diesel engine. With ANSYS FORTRE, they conducted high-pressure jet splitting using KH-RT atomization model. They used the k-epsilon turbulence model to simulate turbulence occurring during the formation of the mixture.

Skogsberg et al. (2007) investigated the spray formation and atomization properties of a piezoelectric energized injector known as having A-nozzle geometry. A high-speed video camera was used with Phase Doppler Anemometry (PDA) to identify the basic mechanisms, droplet sizes and velocities of spray formation. Then, in order to examine these mechanisms in detail, Planar Mie Scattering and Planar Laser Source Fluorescent (LIF) were used. The systems used for the research changed various boundary conditions such as ambient pressure and temperature in the CVCC used in carrying out the experiments and also experimentally examined various injection strategies. They also compared the piezo- energized injector with a multi-hole solenoid driven injector.

Sim et al. (2016) conducted experimental and numerical studies with an externally opened piezo-energized injector. They observed string-like structures at the time of spraying and revealed the missing aspects of the widely used disintegration models. Because the nozzle geometry in the injectors is not well known, they mentioned the importance of estimating the first drop diameter value in modeling studies. In contrast to previous studies suggesting that the first droplet diameter may be equal to the diameter of the injector or needle lift, they have proposed a calculation model for the first droplet diameter value. They also proposed a new modeling technique for more accurate simulation of string-like structures in numerical modeling of fuel fraction.

Shi et al. (2008) performed an experimental and numerical study for a GDI engine with equipped an outwardly-opening cone type injector. In their research, were carried out in a pressurized chamber in spray characterization experiments by using a Mie scattering technique and PDA measurement. In the absence of evaporation, the fuel temperature was initially kept at $-10{ }^{\circ} \mathrm{C}$ and the temperature of the conditioned room were kept constant at $20{ }^{\circ} \mathrm{C}$ and they carried out the experiments with various fuel types. They have obtained spray contours, droplet diameter, and velocity for the various injector and ambient pressures.

The aim of the study was to examine the spray properties of the hollow cone type injector opened to the outside by considering the ambient pressure and temperature at the start of the engine in the cold. The effect of ambient pressure and temperature on spray penetration, fuel spay angle and Sauter Mean Diameter (SMD) was investigated. In the literature, experimental studies have been presented for the cold start situation but no numerical studies have been conducted. Therefore, this study was made to cover this the deficit in the literature. In addition, in our study, it is distinguished from other studies by numerically investigating how piezo triggered injectors used in gasoline engines are affected by ambient conditions under cold working conditions. Numerical studies with ANSYS Fluent software were validated using the experimental results and then numerical results of the parameters were compared.

\section{MATERIALS AND METHODS}

\subsection{Spray Modeling}

Computer-aided engineering software, which is used by researchers and experts, has become widespread with the rapid development of computational capabilities of computers and mathematical modeling based calculation methods and methods in science and engineering. Ansys Fluent software, which is widely used in spray modeling studies, was also used in this study. 
The lack of gasoline and derivative mixtures of the fuel to be used in experimental studies increases the reproducibility and reliability of the experiments. In the simulation studies, nheptane fuel was chosen because of the fact that it does not exhibit unstable properties in fuel blends and all chemical and thermodynamic properties are known. The physical properties of $\mathrm{n}$ heptane fuel are given in Table 1 (Das, 2017). Air is used as the ambient gas. The ambient gas (air) is from the database of the Fluent software. The air consists of carbon dioxide $\left(\mathrm{CO}_{2}\right)$, nitrogen $\left(\mathrm{N}_{2}\right)$, oxygen $\left(\mathrm{O}_{2}\right)$ and water vapor $\left(\mathrm{H}_{2} \mathrm{O}\right)$. However, carbon dioxide and water vapor were not included in the analysis because they were negligible. The air is also considered as the ideal gas.

Table 1. Physical features of n-heptan fuel (Das, 2017)

\begin{tabular}{|c|c|}
\hline Fuel Properties & N-heptan \\
\hline Density at $15^{\circ} \mathrm{C}\left(\mathrm{kg} / \mathrm{m}^{3}\right)$ & 684 \\
\hline Formula & $\mathrm{C}_{7} \mathrm{H}_{16}$ \\
\hline Hydrogen (weigth \%) & 16.1 \\
\hline Carbon (weigth \%) & 83.9 \\
\hline Kinematic Viscosity (cSt) & 0.51 \\
\hline Cetan Number & 56.3 \\
\hline
\end{tabular}

The k- $\varepsilon$ turbulence model from the Reynolds-Averaged Navier-Stokes (RANS) based renormalization group (Realizable) has been used for calculations in numerous research studies in the literature. In addition, liquid parcels (droplet groups) are included in the gas phase calculation area and Lagrangian discrete parcel method is used for spray modeling (Sim et al., 2016).

The hybrid fragmentation model consists of combining at least two different disintegration models. The main idea in the development of hybrid fragmentation models comes from more accurate modeling of primary and secondary atomization. For this reason, Kelvin-Helmholtz / Rayleigh-Taylor (KH-RT) atomization model was used for numerical calculations. This model has been developed to model the deterioration of fuel at high injection pressure as in diesel engines. This atomization model is also preferred because of high spray pressures in modern gasoline engines up to 350 bar. This atomization model deals with atomization in two stages, while the $\mathrm{KH}$ model for the primary atomization model provides a solution in the region near the injector nozzle and with the RT model for the secondary atomization model (Beale and Reitz, 1999; Lefevre and McDonell, 2017). A schematic representation of this atomization model is shown in Figure 1 (Ansys 18.1 Fluent Tutorials, 2019). For more detailed information, see (V. Basshuysen, 2009; Stiesch, 2003; Baumgarten, 2006; Kim et al., 2008; Rotondi and Bella, 2006).

As can be seen from eq. (12), the high pressure causes an increase in the droplet velocity. The increased droplet velocity results in an increase in the number of Weber (We) in eq. (1). This results in more severe fragmentation. 


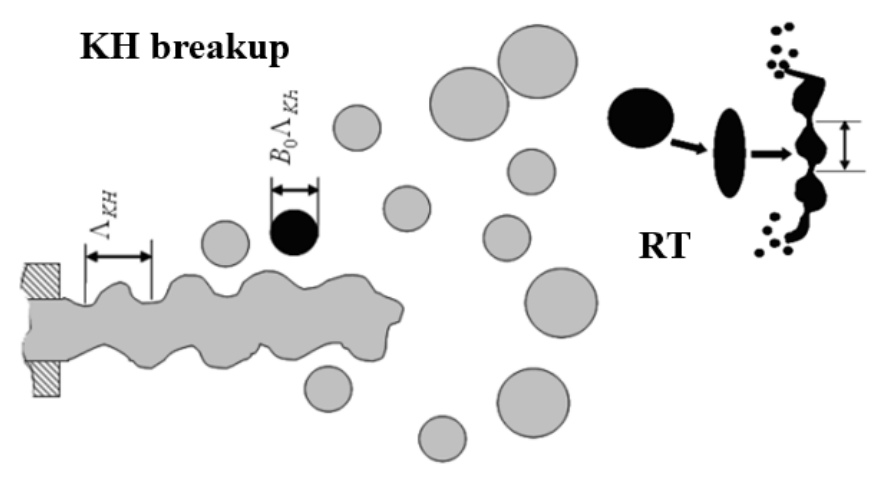

Figure 1:

Schematic representation of KH-RT breakup model (Ansys 18.1 Fluent Tutorials, 2019)

In the following equations $V_{r}$ is the relative velocity between the ambient gas and the droplet velocity and the droplet diameter is $\mathrm{r}$, also here, $\mathrm{f}$ and $\mathrm{g}$ indices indicate fuel and ambient gas, respectively.

$$
\begin{gathered}
W e=\frac{\rho_{g} V_{r} D_{n o z}}{\sigma} \\
Z=\frac{\sqrt{W e_{f}}}{R e_{f}} \\
R e_{f}=\frac{\rho_{f} V_{r}}{\mu_{f}} \\
\frac{T}{\Lambda_{K H}}=\frac{Z}{\sqrt{W e_{g}}} \\
r .02 \frac{\left(1+0.45 Z^{0.5}\right)\left(1+0.4 T^{0.7}\right)}{\left(1+0.87 W e_{g}{ }^{1.67}\right)^{0.6}} \\
\Omega_{K H}\left[\frac{\rho_{f} r^{3}}{\sigma}\right]^{0.5}=\frac{\left(0.34+0.38 W e_{g}^{0.5}\right)}{(1+Z)\left(1+1.4 T^{0.6}\right)}
\end{gathered}
$$

The model's critical droplet radius $r_{c}$ and breakup time $\tau_{K H}$

$$
\begin{gathered}
r_{c}=0.61 \Lambda_{K H} \\
\tau_{K H}=\frac{3.762 B_{1} r}{\Omega_{K H} \Lambda_{K H}}
\end{gathered}
$$


where the KH breakup model constant $B_{1}$ is taken as equal to 40 as recommended by Lee and Park. For more detailed information, see article (Lee and Park, 2002).

As the farther away from the injector nozzle, the Rayleigh-Taylor (RT) disintegration process takes place. In the process of RT fragmentation the droplet diameter $D_{d}$ should be greater than the wavelength of $\Lambda_{R T}$ the fastest growing wave. The relationship between these two variables is expressed by the equation given below.

$$
D_{d}=C_{R T} \Lambda_{R T}
$$

where the $\mathrm{C}_{\mathrm{RT}}$ is from 0.1 to 1.0 .

$$
\begin{gathered}
\Lambda_{R T}=\sqrt{\frac{3 \sigma}{-a\left(\rho_{l}-\rho_{g}\right)}} \\
\Omega_{R T}=\sqrt{\frac{2}{3 \sqrt{3 \sigma}} \frac{\left[-a\left(\rho_{l}-\rho_{g}\right)\right]^{1.5}}{\rho_{l}+\rho_{g}}}
\end{gathered}
$$

\subsection{Validation}

In the determination of the coefficients related the KH-RT fragmentation model, i.e. the calibration of the injector, the experimental study in the literature has been utilized. The boundary conditions, injector spray and ambient pressure of the tests are 200 and 5 bar, respectively (Şentürk, 2015). For the time to inject the injector and the time taken for the images, the values in the Şentürk (2015) study were accepted as reference. These values are 1000 and 700 microseconds, respectively (Şentürk, 2015).

The spray angle determination in boundary conditions according to Bosch norms is described as follows. At the maximum needle opening, an arc is drawn which will be tangent to $5 \mathrm{~mm}$ below the needle upper surface. The drawn arc is intersected with the edges of the fuel cloud. The arc radius is considered as the fuel beam angle. For more details on how to perform other measurements of the spray cloud characteristic, see (Şentürk, 2015).

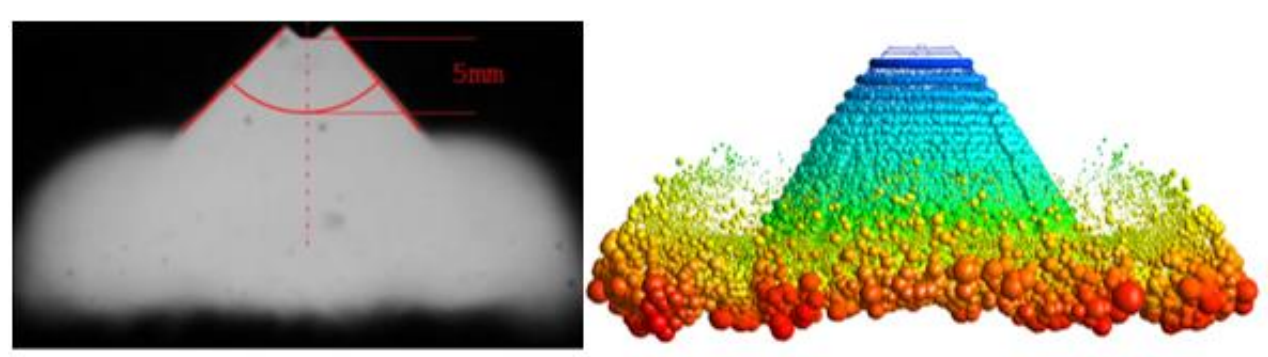

Figure 2:

Comparison of simulation and experimental result

As a result of validation studies for the current experimental work, the breakdown model constants and ambient test conditions are given in Table 2 and Table 3, respectively. 
Table 2. KH-RT atomization model parameters

\begin{tabular}{|c|c|}
\hline Parameters & Value \\
\hline KH-RT & - \\
\hline $\mathrm{B}_{0}$ & 0.61 \\
\hline $\mathrm{C}_{\mathrm{RT}}$ & 0.10 \\
\hline $\mathrm{C}_{\tau}$ & 0.50 \\
\hline $\mathrm{B}_{1}$ & 40 \\
\hline $\mathrm{C}_{\mathrm{L}}$ & 5 \\
\hline
\end{tabular}

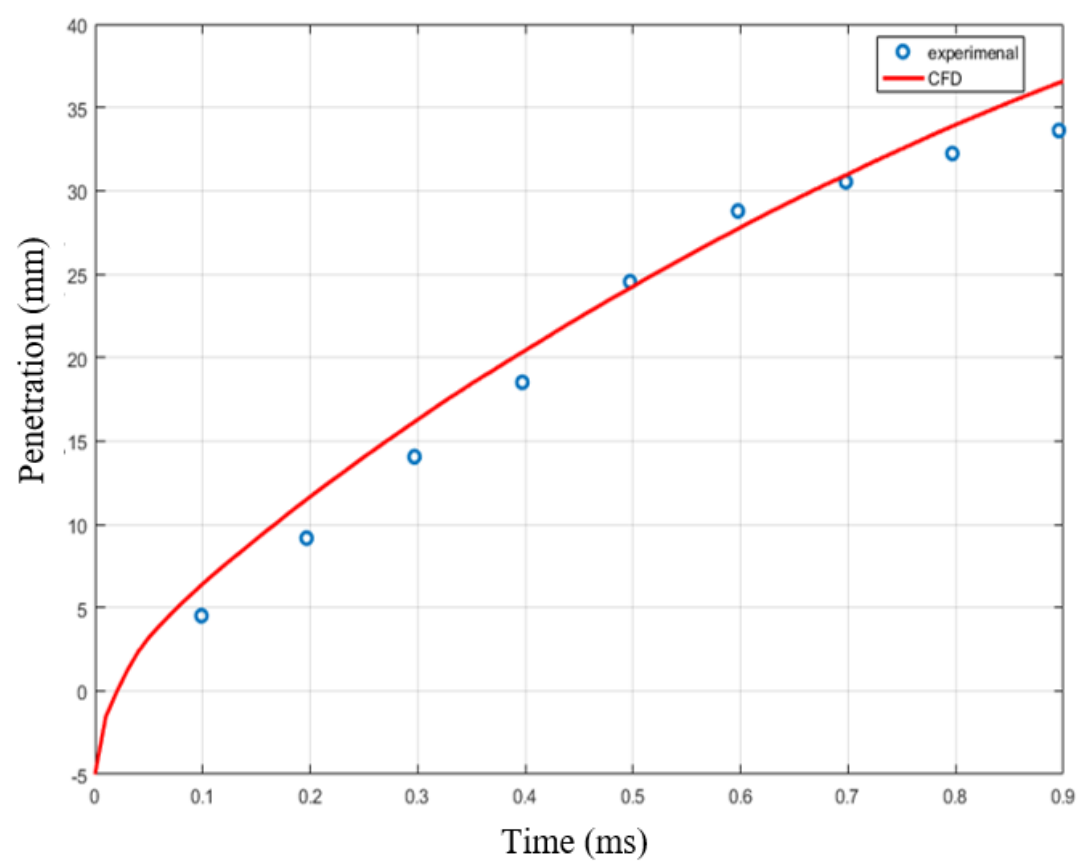

Figure 3:

Comparison of experimental data and simulation results according to the depth of penetration (Experimental data were obtained from Zheng, 2013.)

In addition, the penetration depth, which is one of the important characteristics of the fuel spray, is widely used in calibration studies. Figure 4 shows the change in the penetration depth of the spray cluster depending on time. In the calibration studies carried out with KH-RT breakup model constants given in Table 2, experimental results and numerical results are observed to be in harmony.

\subsection{Outwardly-Opening Injector}

The outward-opening hollow cone type injectors used in GDI engines respond precisely and very fast even at high operating pressures. As shown in Figure 3, the needle is opened out and the needle lift amount is maximum $35 \mu \mathrm{m}$ and the needle diameter is $4 \mathrm{~mm}$ (Mathieu et al., 2010). By controlling the needle lift and energized times, the mass flow of the fuel exiting the injector is controlled. In order to calculate the flow rate of the fuel according to the mass fuel flow formula, it is necessary to know the fuel discharge rate, density and the cross-sectional area of the injector. 


$$
V_{i n j}=C_{D} \sqrt{\frac{2\left(P_{i n j}-P_{c h}\right)}{\rho_{l}}}
$$

The theoretical velocity value can be obtained by writing the Bernoulli Equation between the combustion chamber $\left(P_{c h}\right)$ and the injector pressure $\left(P_{i n j}\right)$ to calculate the output velocity. The actual velocity $\left(V_{i n j}\right)$ can be obtained by multiplying the theoretical velocity by the injector discharge rate. The discharge coefficient $\left(C_{D}\right)$ varies between 0.7 and 0.78 according to number of (Sim et al., 2016). In this study, the $C_{D}$ was taken as 0.75 .

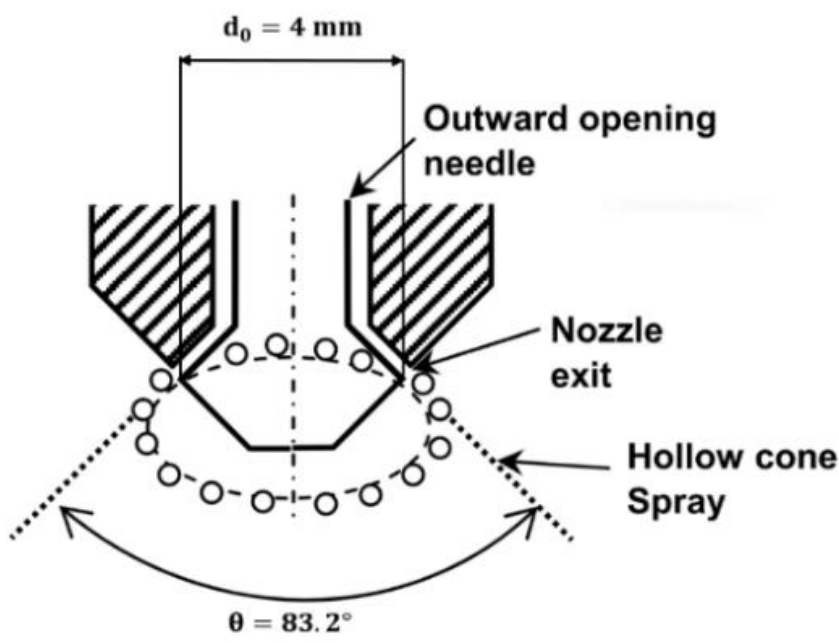

Figure 4:

Schematic representation of the outward opening hollow cone

In numerical spray modeling studies, the initial SMD value is as important as the correct estimate of the minimum injector output speed. The initial SMD value of the injector was determined to be equal to $90 \%$ of the maximum needle lift amount (Sim et al., 2016).

The injector was energized over $1000 \mu \mathrm{s}$ and fuel injection continued during this time. Evaporation and fuel bundle distortion is increasing gradually as spraying continues. This makes it difficult to carry out the specified measurements. Therefore, when measuring the velocity vectors and the spray cone angle, images will be taken after $700 \mu \mathrm{s}$ after the start of spraying.

\subsection{Mesh Structure and Boundary Conditions of Simulation}

While this geometry was generated, the combustion chamber volume of the internal combustion engines and the spray injected during the fuel injection were determined to be so large that they could not come into contact with the combustion chamber walls. In the simulation studies, a cylindrical geometry with a diameter of $80 \mathrm{~mm}$ and a height of $55 \mathrm{~mm}$ was determined for the calculation domain. If this domain is designed to be larger than what is required, the calculation domain increases so the calculation time increases. Therefore, the most appropriate sizing process has been performed (Huang and Lipatnikov, 2011).

If the spray point is started on the surface in the full top plane of the cylinder, there is a convergence problem during the solution. Therefore, the injection point is inside the calculation area with a cylindrical volume and is thought to be $5 \mathrm{~mm}$ below the top of the cylinder center (Huang and Lipatnikov, 2011). Also, the injector body is not included in the calculation volume. Therefore, it is not modeled for the spraying point. The type and size of the mesh structure is 
Cut Cell and $1.5 \mathrm{~mm}$, respectively. The total number of elements is 85692 . The visual representation of the calculation volume is given in Figure 4.

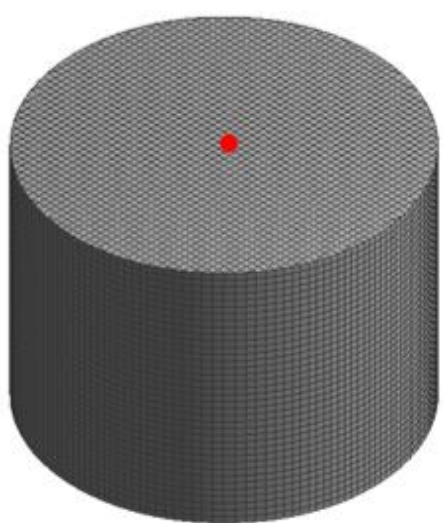

$a$.

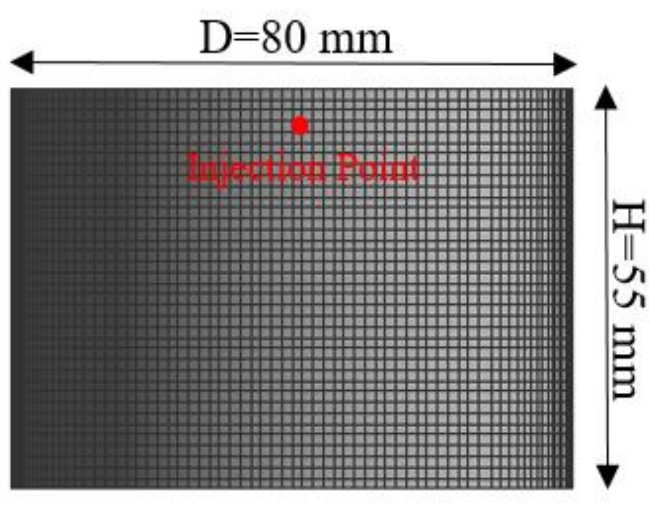

$b$.

Figure 5:

Calculation domain and injection point;
a. Isometric view
b. Left view

For the simulation boundary conditions, the injector pressure was kept constant at 350 bar and the pressure and temperature of the environment where the fuel was sprayed was changed. Simulation boundary conditions are given in Table 3.

Table 3. Boundary conditions for simulation

\begin{tabular}{|c|c|}
\hline Variables & Value \\
\hline Ambient Pressure (bar) & $5,10,15,20$ \\
\hline Ambient Temperature (K) & $243,253,263,273,283,293,303,313$ \\
\hline
\end{tabular}

These parameters are chosen in order to determine the effect of the engine on the fuel-air mixture condition, spray characterization and shape during extreme cold climate/weather conditions or in environments with these atmospheric conditions.

\section{RESULTS AND DISCUSSION}

\subsection{Effect of Ambient Temperature on SMD}

The fuel droplets interact with the ambient as they move through the ambient and the aerodynamic forces begin to influence the fuel particles due to the relative speed between the droplet and the surrounding and this enforce the fuel particles to deformation. If a sufficiently large force affects the fuel particle, the fuel droplets begin to disintegrate. The shattered large fuel droplets produce smaller fuel particles. The ratio of the total volume of these fuel particles to the total surface area, which is known as the SMD, indicates that atomization of the spray has improved.

As can be seen from Figure 5, while the ambient pressure was kept constant, increasing the ambient temperature allowed the SMD to tend to shrink. Increasing the ambient temperature allows the fuel particles to get more energy so that the evaporation of the fuel becomes easier and the average diameter decreases. Şentürk (2015), reported that the SMD diameter value for 
Taş I.,Karamangil M.I...: Num. Inv. Of The Spr. Char. In OutWrd-Opn. Piezoel. Gas Inj. For Dif. Amb. Cond.

piezo energized injector is 10-15 $\mu \mathrm{m}$. In addition, Iyer et al. (2004) presented similar results for the SMD diameter of $14.3 \mu \mathrm{m}$.

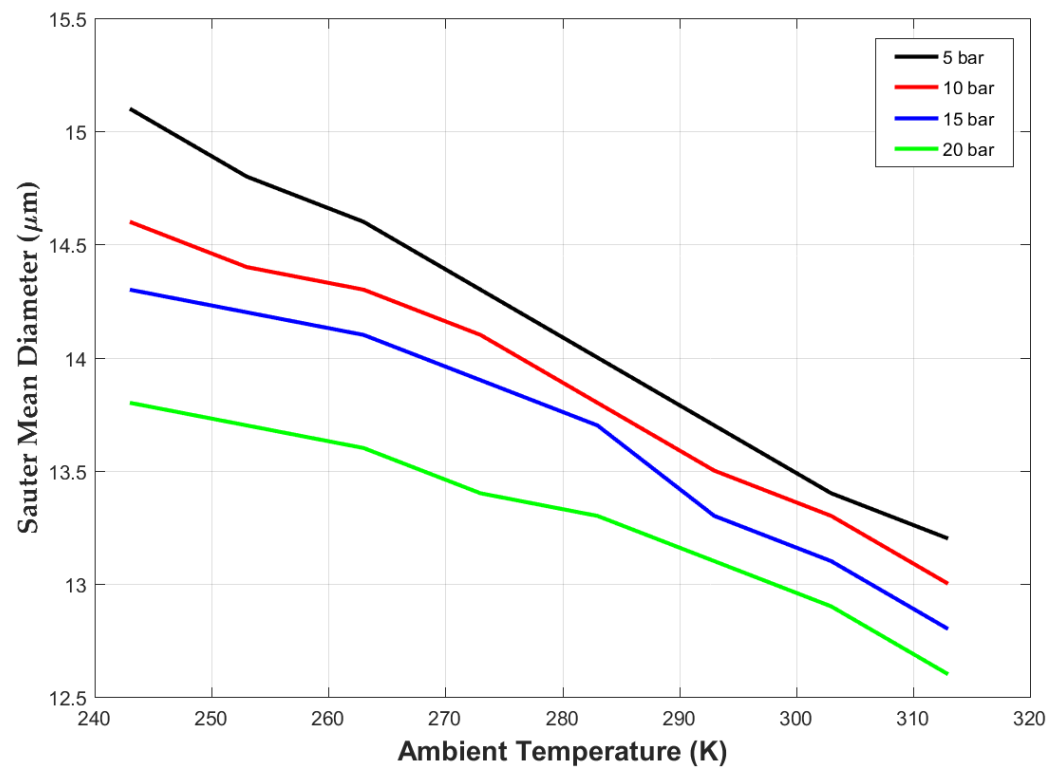

Figure 6:

Effect of ambient temperature on SMD

\subsection{Effect of Ambient Pressure on SMD}

The effect of ambient pressure on the droplet diameter indicated that the increase in ambient pressure caused the aerodynamic forces to increase. Increasing the pressure of the environment causes more intensive environmental conditions. Fuel means that droplets will be subject to more severe degradation as a result of contact with the site-intensive environment. As it is understood from Figure 6, the atomization intensity increases with the increasing pressure at the same ambient temperature and thus the SMD value decreases.

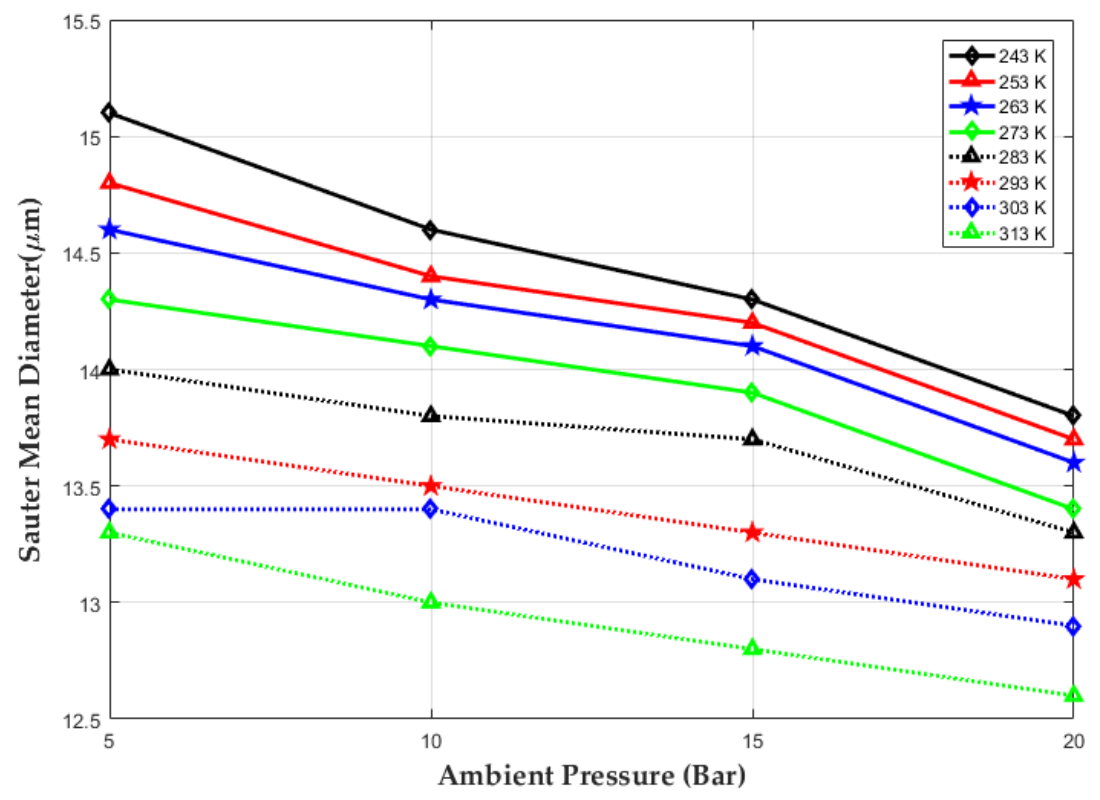

Figure 7:

Effect of ambient pressure on SMD 


\subsection{Effect of Ambient Temperature and Pressure on Spray Penetration}

The farthest distance that fuel can travel in the cylinder is of great importance in terms of both fuel air mixture and unburned hydrocarbon (UH) and soot emissions. It is not desirable for the fuel discharged from the injector to hit the cylinder walls or the piston plate. This affects hydrocarbon household emissions. On the other hand, it is desirable for fuel particles leaving the injector to reach sufficiently distant distances. For the fuel air mixture to be sufficiently rich in the vicinity of the spark plug, the fuel must reach an appropriate amount in this region. If the proper fuel-air mixture does not occur in the vicinity of the spark plug occurs event that is known as misfiring. In other words, the unburned fuel is removed from the cylinders and the unburned hydrocarbon emissions are increased. For these reasons, the spraying efficiency is of great importance in the formation of the mixture (V. Basshuysen, 2009; Dahlander et al., 2008; Dong et al., 2013; Park et al., 2002).

At increased ambient pressure, the fuel delivery rate of the injector is reduced due to a decrease in the difference between the ambient pressure and the injector pressure. This is given in eq. (12). In addition to the decrease in velocity, the increase in the ambient density increases the intensity of the aerodynamic forces which strengthen the splitting. With the increase of the fraction, the fuel droplets are separated into smaller pieces and rapidly evaporate by drawing energy from the environment. Reduces the momentum of the droplet with the decrease in speed and the stronger evaporation of the droplets.

More severe vortices in the fuel bundle that interacts with the environment more violently. In this way, the kinetic energy of the fuel bundle turns into the rotation and the spray depth is reduced. The results of this situation are given in Figure 7 (Kim et al., 2008; Schmid, 2012; Das, 2008; Stiehl et al., 2013; Migliaccio et al., 2017). 


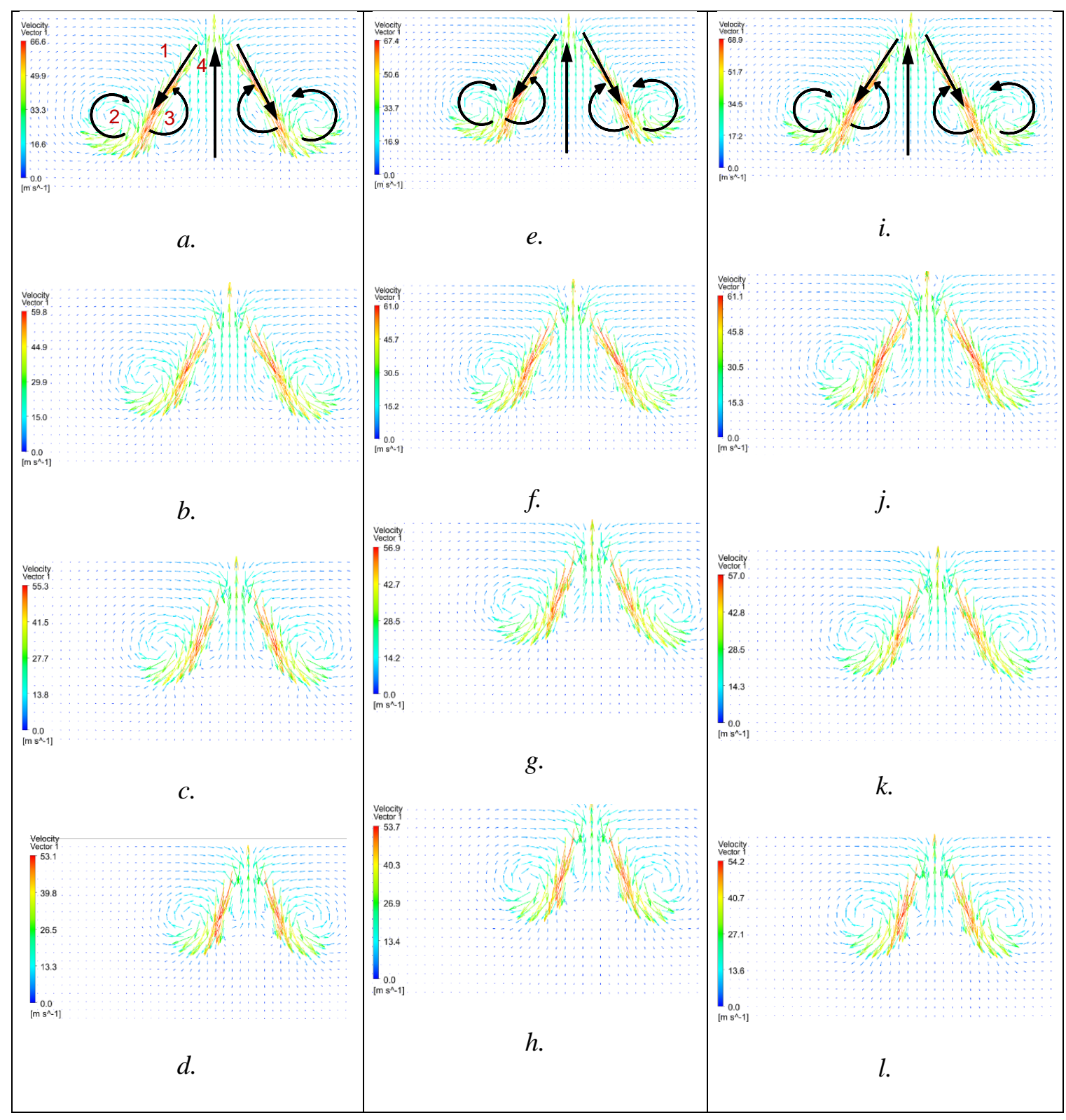

Figure 8:

Velocity vector based on ambient pressure and temperature

a. 5 bar $243 \mathrm{~K}$, b. 10 bar $243 \mathrm{~K}$, c. 15 bar $243 \mathrm{~K}$, d. 20 bar $243 \mathrm{~K}$, e. 5 bar $263 \mathrm{~K}$, f. 10 bar 263 K, g. 15 bar 263 K, h. 20 bar 263 K, i. 5 bar 283 K, j. 10 bar 283 K, k. 15 bar 283 K, l. 20 bar $283 \mathrm{~K}$

The fuel spray form can be investigated by dividing into 4 zones as shown in Figure 7 . The velocity vectors in each region are shown in Figure $7 \mathrm{a}-1$ for different ambient pressures and temperatures. (1) is the region forming the hollow cone through the needle. (2) shows the vortex region formed in the opposite direction at the fuel spray tip due to the air resistance. (3) is the vortex formed by the stream moving in direction 4. (4) is the flow region from the center to the needle.

In Figure $7 \mathrm{a}-7 \mathrm{~d}$, at $243 \mathrm{~K}$ constant temperature and different ambient pressures ( 5 bar, 10 bar, 15 bar and 20 bar), the velocity values of the fuel spray in the direction of the arrow "1" were $66.6 \mathrm{~m} / \mathrm{s}, 59.6 \mathrm{~m} / \mathrm{s}, 55.3 \mathrm{~m} / \mathrm{s}$ and $53.1 \mathrm{~m} / \mathrm{s}$, respectively. The increased ambient pressure 
reduced the fuel spray speed in direction 1. Similarly, in Figure 7i-71 at $283 \mathrm{~K}$ constant temperature and different ambient pressures ( 5 bar, 10 bar, 15 bar and 20 bar), the velocity values of the fuel spray in the direction of the arrow " 1 " were $68.9 \mathrm{~m} / \mathrm{s}, 61.1 \mathrm{~m} / \mathrm{s}, 57.0 \mathrm{~m} / \mathrm{s}$ and $54.2 \mathrm{~m} / \mathrm{s}$, respectively. As the temperature increase decreases the density of the environment, there has been a slight increase in the velocity. Speed vectors of other regions (2, 3 and 4) can be investigated from graphics.

Figure 8 shows that the spray penetration decreases with increasing ambient pressure at the same temperature. On the other hand, there was an increase in spray penetration with increasing temperature at the same ambient pressure. An increase in ambient temperature will result in a decrease in the density of gas, provided that the amount of the gas and the ambient pressure remain the same. The decrease in density will reduce the resistance forces acting on the fuel particles, so it will be difficult to disintegrate the fuel. As the bundle of non-fractured fuel can reach more distant points, an increase in spray depth occurs (V. Basshuysen, 2009; Stiesch, 2003; Baumgarten, 2006; Schmid, 2012).

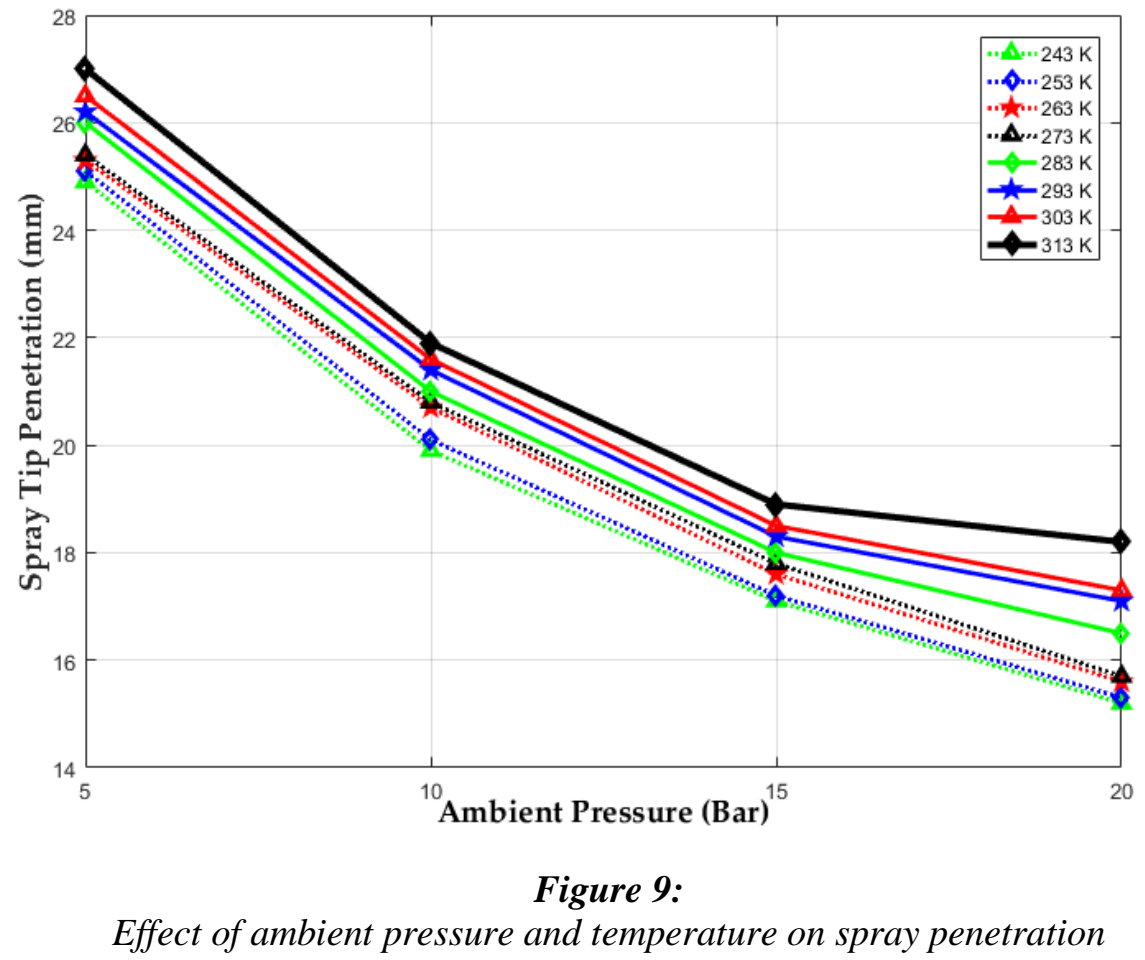

\subsection{Effect of Ambient Temperature and Pressure on Evaporation Rate}

The boiling point of liquids such as fuels varies depending on the environment pressure. Increasing ambient pressure is expected to increase with boiling point and a decrease in evaporation percentage. However, the increase in ambient pressure allows the viscous forces to be more effective. Thus, the process of disintegration is easier and the percentage of evaporation has increased. In addition, this situation decreases the value of SMD and hence also affects the quality of the mixture formation (Sim et al., 2016).

As can be seen from the graph in Figure 9, the evaporation rate increased with increasing temperature. In addition, evaporation became more effective by increasing the ambient pressure. 


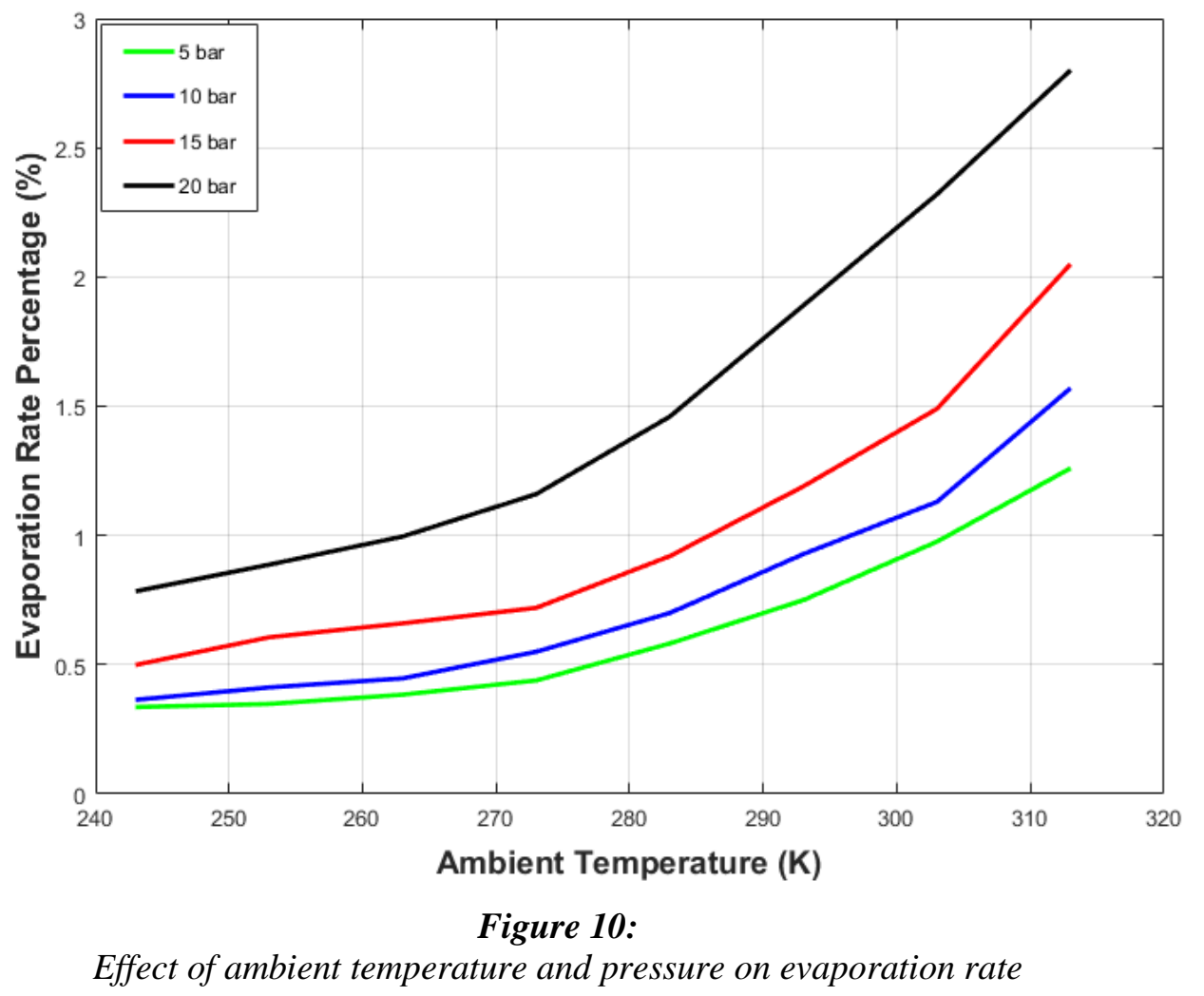

Another point is that if the vertical axis is followed in the horizontal axis for any constant temperature in Figure 9, the pressure increases and the effect on evaporation is higher. For example, for a constant temperature of $303 \mathrm{~K}$, at 5 bar, 10 bar, 15 bar and 20 bar ambient pressures, the evaporation rates are $0.97,1.13,1.49,2.25$ respectively. The difference between the given values is increasing and this shows the greater role of evaporation in ambient pressure.

\subsection{Effect of Ambient Temperature and Pressure on Spray Morphology}

The image shown in Figure 10 is arranged according to the spray penetration and with the increasing ambient pressure, the spray cloud appears to be compact in a narrower volume. The compactness of the fuel cloud allows the formation of a fuel-air mixture in a narrower area (Park et al., 2002).

If Figure 10 is carefully examined, the distance between the region where the spraying begins (where the blue color) and the point where the fuel cloud reaches (where the red color here) is reduced depending on the increased ambient pressure. In addition, the vortex regions of the spray bundle were agglomerated with increasing ambient pressure. With increasing ambient pressure, the larger amount of the fuel bundle is encapsulated in this ellipse. For example, in the images indicated by (a), (b), (c), (d), the ambient temperature is the same and the pressures are $5,10,15,20$ bars in order. On the other hand, the increase in the ambient temperature was not as effective as the pressure on the compacting of the fuel cloud. The ambient pressures in the images indicated by (a), (e), (i) are the same and the temperatures are $243 \mathrm{~K}, 263 \mathrm{~K}, 283 \mathrm{~K}$, respectively (Iyer et al., 2004; Park et al., 2002; Schmid et al., 2010). 


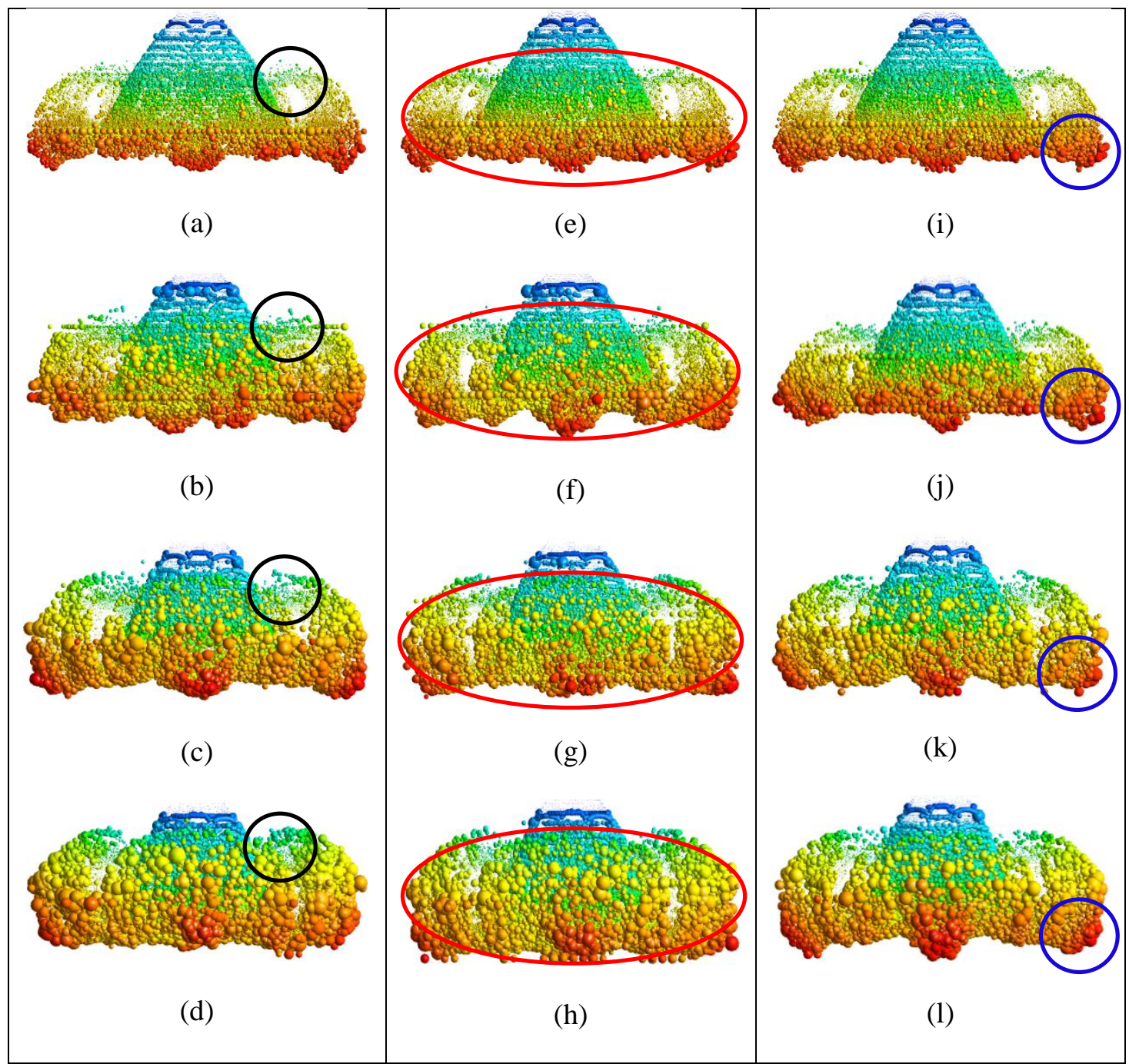

Figure 11:

Spray tip penetration and change of droplet diameters depending on ambient pressure and temperature

a. 5 bar 243 K, b. 10 bar 243 K, c. 15 bar 243 K, d. 20 bar 243 K, e. 5 bar 263 K, f. 10 bar 263 K, g. 15 bar $263 \mathrm{~K}, \boldsymbol{h} .20$ bar $263 \mathrm{~K}, \boldsymbol{i} .5$ bar $283 \mathrm{~K}, \boldsymbol{j} .10$ bar $283 \mathrm{~K}, \boldsymbol{k} .15$ bar $283 \mathrm{~K}, \boldsymbol{l} .20$ bar $283 \mathrm{~K}$

Figure 10 shows that the droplet diameters increase with the increase of ambient pressure in the regions shown with black circles. This increased the possibility of the droplets colliding with each other because the pressure in the environment increased and the fuel cloud became more compact. This explains that droplets in these regions (black circular region) have a larger diameter (Schmid, 2012; Oh et al., 2012). On the other hand, while the end portions of the large vortices have small droplet diameters, the droplet diameters of the sprayer end regions (the area shown in the blue circular) are larger (Schmid, 2012). 


\section{CONCLUSION}

In this study, calibration studies of a piezo-triggered gasoline injector with 350 bar spray pressure and A-nozzle geometry were investigated numerically with Ansys Fluent software. Using the parameters of this injector, the effect of ambient pressure and temperature on the spray shape, Sauter Mean Diameter (SMD), spray depth and evaporation rate were investigated. Results of the study:

1) The Sauter Mean Diameter (SMD) is reduced while the ambient temperature and pressure increase.

2) With the increase of ambient pressure, it decreased the speed of the fuel leaving the injector and thus reduced the amount of penetration.

3) As expected, increasing the ambient temperature, the rate of evaporation increased, but the increase in ambient pressure was found to be more effective on the evaporation rate.

4) The fuel cluster has become more compact when the ambient pressure is increased. This increased the probability of collision of the droplets in the lower vortex region of the fuel bundle. For this reason, an increase in the diameters of the fuel droplets in the region has been observed, and also the diameters of the fuel droplets in the vortex end zone have increased.

5) The temperature parameter does not show a significant change on the fuel cluster shape.

\section{Nomenclature}

$\begin{array}{ll}C_{d} & \text { Discharge coefficient } \\ P & \text { Pressure } \\ \mathrm{V} & \text { Velocity } \\ \mathrm{r} & \text { Radius } \\ \mathrm{D} & \text { Diameter } \\ R e & \text { Reynolds number } \\ T & \text { Taylor number } \\ W e & \text { Weber number } \\ Z & \text { Ohnesorge number }\end{array}$

$$
\begin{array}{ll}
\text { Greek symbols } \\
\theta & \text { hollow cone angle } \\
\sigma & \text { surface tension } \\
\Lambda & \text { wavelength } \\
\rho & \text { density } \\
\tau & \text { time } \\
\mu & \text { dynamic viscosity }
\end{array}
$$

\section{Subscript}

$0 \quad$ initial

c critical

ch chamber

d droplet

$g \quad$ gas

$l \quad$ liquid

inj injection

noz nozzle

$r \quad$ relative (gas-liquid)

KH Kelvin-Helmholtz

$R T$ Rayleigh-Taylor 


\section{REFERENCES}

1. Ansys Workbench Fluent 18.2 Tutorials, (2019) Sharcnet Available Online: https://www.sharcnet.ca/Software/Ansys/18.2.2/en-us/help/forte_th/i44073.html

2. Baumgarten, (2006) Mixture Formation in Internal Combustion Engines, Springer-Verlag Berlin and Heidelberg GmbH\&Co. KG, Berlin.

3. Beale, J., Reitz, R.D. (1999) Modeling Spray Atomization with the KelvinHelmholtz/Rayleigh-Taylor Hybrid Model, Atomization and Sprays, 9, 623-650. doi: 10.1615/AtomizSpr.v9.i6.40.

4. Dahlander, P., Gutkowski, A., Denbratt, I. (2008) Visualization of Fuel Sprays for Stratified Cold Starts in Gasoline Direct Injection Engines, 22rd European Conference on Liquid Atomization and Spray Systems, Como Lake, Italy. Available Online: http://www.ilasseurope.org/ICLASS/ILASS2008_COMO/file/papers/10-4.pdf

5. Das, S. (2008) Fluid Dynamic Study of Hollow Cone Sprays, SAE Tech. Paper Series 200801-0131. doi:10.4271/2008-01-0131.

6. Dong, Q., Ishima, T., Kawashima, H., Long, W. (2013) A Study on the Spray Characteristics of a Piezo Pintle-Type Injector for DI Gasoline Engines, J. Mechanical Sci. and Techology 27, 7, 1981-1993. doi:10.1007/s12206-013-0510-3.

7. Huang, C., Lipatnikov, A. (2011) Modelling of Gasoline and Ethanol Hollow-Cone Sprays Using OpenFOAM, SAE Tech. Paper Series 2011-01-1896. doi:10.4271/2011-01-1896.

8. Iyer, C.O., Han, Z., Yi, J. (2004) CFD Modeling of a Vortex Induced Stratification Combustion (VISC) System, SAE Tech. Paper Series 2004-01-0550. doi:10.4271/2004-010550 .

9. Kim, S.J., Kim, Y.N., Lee, J.H. (2008) Analysis of the In-Cylinder Flow, Mixture Formation and Combustion Processes in a Spray-Guided GDI Engine, SAE Tech. Paper Series 2008-01-0142. doi:10.4271/2008-01-0142.

10. Lefevre and McDonell, (2017) Atomization and Sprays, CRC Press, New York.

11. Lee, C.S., Park, S.W. (2002) An Experimental and Numerical Study on Fuel Atomization Characteristics of High-Pressure Diesel Injection Sprays, Fuel, 2417-2423. doi:10.1016/S0016-2361(02)00158-8.

12. Mathieu, F., Reddemann, M., Martin, D., Kneer, R. (2010) Experimental Investigation of Fuel Influence on Atomization and Spray Propagation Using an Outwardly Opening GDIInjector, SAE Tech. Paper Series 2010-01-2275. doi:10.4271/2010-01-2275.

13. Migliaccio, M., Montaaro, A., Batrice, C., Napolitano, P., Allocca, L., Fraioli, V. (2017) Experimental and Numerical Analysis of a High-Pressure Outwardly Opening Hollow Cone Spray Injector for Automotive Engines, Fuel, 196, 508-519. doi: 10.1016/j.fuel.2017.01.020.

14. Oh, Y., Lee, S., Kigdm, D., Chon, M., Park, S. (2012) Experimental and Numerical Study on Spray Characteristics of Multi-Hole Type GDI Injectors, Available Online: http://www.ilass.org/2/conferencepapers/81.pdf

15. Park, S.W., Kim, H.J., Lee, C.S. (2002) An Experimental and Numerical Study on Atomization Characteristics of Gasoline Injector for Direct Injection Engine, $15^{\text {th }}$ Annual Conference on Liquid Atomization and Spray Systems, Madison, USA.

16. Pielecha, I. (2014) Modeling of Gasoline Fuel Spray Penetration in SIDI Engines, Int. J. Automotive Technology, 15, 47-55. doi:10.1007/s12239-014-0005-y. 
Taş I.,Karamangil M.I...: Num. Inv. Of The Spr. Char. In OutWrd-Opn. Piezoel. Gas Inj. For Dif. Amb. Cond.

17. Rotondi, R., Bella, G. (2006) Gasoline Direct Injection Spray Simulation, Int. J. Thermal Science, 45, 168-179. doi:10.1016/j.ijthermalsci.2005.06.001.

18. Stiesch, (2003) Modeling Engine Spray and Combustion Processes, Springer-Verlag Berlin and Heidelberg GmbH\&Co. KG, Berlin.

19. Skogsberg, M., Dahlander, P., Denbratt, I. (2007) Spray Shape and Atomization Quality of an Outward-Opening Piezo Gasoline DI Injector, SAE Tech. Paper Series 2007-01-1409. doi: 10.4271/2007-01-1409 .

20. Sim, J., Badra, J., Elwardany, A., Im, H. (2016) Spray Modeling for Outwardly-Opening Hollow-Cone Injector, SAE Tech. Paper Series 2016-01-0844. doi:10.4271/2016-01-0844.

21. Shi, J., Baecker, H., Tichy, M., Bauer, W. (2008) Numerical and Experimental Investigation of Fuel Injection and Dropler Evaporation in a Pressure Chamber for the Development of Gasoline Direct Injection, 22rd European Conference on Liquid Atomization and Spray Systems, Como Lake, Italy.

22. Schmid, A., Mojtabi, M., Wigley, G. (2010) Experimental Investigation on the Spray Behavior for a Hollow Cone Piezo Injector with a Multiple Injection Strategy, 23rd Annual Conference on Liquid Atomization and Spray Systems, Brno, Czech Republic.

23. Schmid, A.M. (2012). Experimental Characterization of the Two Phase Flow of a Modern, Piezo Activated Hollow Cone Injector, Ph.D. Dissertation, ETH ZURICH of University, Poly, Zurich.

24. Stiehl, R., Schorr, J., Krüger, C., Dreizler, A., Böhm, B. (2013) In-Cylinder Flow and Fuel Spray Interactions in a Stratified Spray-Guided Gasoline Engine Investigated by HighSpeed Laser Imaging Techniques, Flow Turbulence Combustion, 91, 431-450. doi: 10.1007/s10494-013-9500-X.

25. Zheng, Y. 2013. Simulations and Experiments of Fuel Injection, Mixing and Combustion in DI Gasoline Engines. Ph.D. Thesis, Wayne State University, Detroit, Michigan.

26. SSentürk, G. (2015) Piezo Teknolojili Benzin Enjektörlerinde Püskürtme Karakteristiklerinin İncelenmesi, Master Dissertation, B.U.Ü. Fen Bilimleri Enstitüsü, Bursa.

27. V. Basshuysen, R. (2009) Gasoline Engine with Direct Injection: Processes, Systems, Development, Potential, Springer-Verlag Berlin and Heidelberg GmbH\&Co. KG, Weisbaden.

28. Wang, X. (2018) Numerical Simulation of the Gasoline Spray with an Outward-Opening Piezoelectric Injector: A Comparative Study of Different Breakup Models, SAE Tech. Paper Series 2018-01-0272. doi:10.4271/2018-01-0272. 